\section{A NEW METHOD OF TESTING MITRAL VALVE FLOW} CHARACTERISTICS

JOHN WRIGHT This has been evolved with a modified pulse duplicator and the use of a hot film probe for measuring velocity, direction, and turbulence. Many of the commercially available mitral valve prostheses are being investigated for their flow characteristics. In addition, efficiency is being examined and some unusual findings point to the possibility of a hydraulic ram effect in the normal mitral valve that allows opening to commence before the end of ventricular systole.

\section{TRIAL OF A NEW ANTI-MYXOVIRUS COMPOUND}

J. E. STARK Two hundred and sixty-four male students living in a hall of residence volunteered to take part in the trial and were randomly allocated into two groups. One group received a synthetic isoquinoline derivative (UK. 2371) daily in divided doses and the other group received identical placebo tablets.

During the five weeks of the trial tablets were distributed daily and volunteers were asked to return any tablets which had not been taken. As an additional guide to tablet acceptance a small quantity of isoniazid was incorporated into some active and placebo tablets and urine samples collected at appropriate times were tested for isoniazid derivatives.

Volunteers were questioned each week about their health and were asked to report all respiratory and other illnesses. All respiratory illnesses were fully investigated for virus and mycoplasma infections. Full toxicity studies were carried out.

The preliminary findings are reported with particular reference to (1) protection against acute respiratory illness provided by the drug; (2) assessment of the novel isoniazid marker system; and (3) the factors affecting acceptance of medication by volunteers.

\section{MYCOPLASMA PNEUMONIAE}

M. C. JONES A retrospective study was made of 100 cases of infection with Mycoplasmn nnelumoniae notified through the Public Health Laboratory four-weekly review during 1967-68, and diagnosed by isolation or complement fixation studies. The mode of presentation, physical, radiological and haematological findings, complications, treatment, and progress are reported.

The results are also presented of an investigation into the isolation rate of Mycoplasma species (including pneumoniae, hominis, orale, and salivarium) from the nasopharynx of patients admitted to hospital with acute exacerbations of asthma, bronchitis or bronchiectasis and from the nasopharynx and bronchial tree of patients submitted to bronchoscopy.

BLOOD LEUCOCYTES DURING EXERCISE IN TUBERCULOUS PATIENTS AFTER GASTRECTOMY

AKE HANNGREN and TORE STRANDELL An increased incidence of tuberculosis in patients with gastrectomy has been found in repeated studies. A correlation between tuberculosis and poor nutrition in patients with the dumping syndrome has been found. It has been suggested that patients suffering from gastric insufficiency have an impaired immunological defence expressed as absence of leucocytosis in febrile infections. The number of leucocytes in the blood at rest, however, is not representative of the total number of leucocytes in the body. During stress, such as after adrenaline injection or during exercise, high leucocyte counts in blood have been recorded and this has been attributed to a redistribution of leucocytes from other parts of the body.

The leucocyte count was determined at rest and during a 30-minute exercise period in gastrectomized and nongastrectomized patients with pulmonary tuberculosis. The increase with exercise of polynuclear and of the total number of leucocytes was less $(P<0.05)$ in the gastrectomized group. No relationship of significance could be observed between different absorption tests and the increase of leucocytes. The number of leucocytes at rest and during exercise was correlated $(P<0.05)$ with the concentration of gamma globulin and tuberculin reactivity: those with weak reactivity and low gamma globulin concentration had low leucocyte counts.

\section{HEAT LOSS DURING THORACOTOMY}

J. A. DYDE and H. F. LUNN A heat debt incurred during an operation necessitates an increase in metabolic rate after operation. Moreover the strict avoidance of a heat debt during and after operation greatly reduces the usual 'metabolic response to trauma'.

We measured the heat debt incurred during thoracotomy, first with no particular measures taken to prevent heat loss and, secondly, using a heat-reflecting aluminium foil blanket wrapped around the lower half of the patient.

Our method of measuring heat loss was adapted from that of Burton and Benzinger. Deep body, calf, forearm, and abdominal skin temperatures were measured. From these readings the average body temperature and the change in heat content were calculated.

Our results are of interest for several reasons:

1. The average heat debt without precautions against heat loss was $20 \mathrm{Kals}$ per hour. This involves a doubling of the metabolic rate to repay the debt.

2. The average heat loss when the blanket was used was $4 \mathrm{Kals}$ per hour.

3. If the blanket was used when the ambient temperature was $23^{\circ} \mathrm{C}$. or above, many patients gained heat.

4. It appears that, if a heat debt is incurred and peripheral vasoconstriction results, the rise in deep body temperature commonly seen after trauma is exaggerated.

5. When the patient was in heat balance and the skin was vasodilated, urine was usually secreted in satisfactory amounts and the circulating blood volume was easier to assess.

\section{THE GLOMUS PULMONALE}

\section{Outline of the Problem}

DONALD HEATH The existence of glomic tissue in close association with the pulmonary trunk and small pulmonary veins, in man and animals. Its possible chemo- 